\title{
Understanding of latent tuberculosis, its treatment and treatment side effects in immigrant and refugee patients
}

Katie Butcher ${ }^{1}$, Beverley-Ann Biggs ${ }^{1,2}$, Karin Leder $^{2,3}$, Chris Lemoh ${ }^{1,2}$, Daniel O'Brien ${ }^{2,4}$ and Caroline Marshall ${ }^{1,2^{*}}$

\begin{abstract}
Background: Isoniazid treatment of latent tuberculosis infection (LTBI) is commonly prescribed in refugees and immigrants. We aimed to assess understanding of information provided about LTBI, its treatment and potential side effects.

Methods: A questionnaire was administered in clinics at a tertiary hospital. Total Knowledge (TKS) and Total Side Effect Scores (TSES) were derived. Logistic regression analyses were employed to correlate socio-demographic factors with knowledge.

Results: Fifty-two participants were recruited, 20 at isoniazid commencement and 32 already on isoniazid. The average TKS were 5.04/9 and 6.23/9 respectively and were significantly associated with interpreter use. Approximately half did not know how tuberculosis was transmitted. The average TSES were 5.0/7 and 3.5/7 respectively, but were not influenced by socio-demographic factors.

Conclusions: There was suboptimal knowledge about LTBI. Improvements in health messages delivered via interpreters and additional methods of distributing information need to be developed for this patient population.
\end{abstract}

Keywords: Latent tuberculosis infection, Health literacy, Immigrant, Refugee

\section{Background}

The global epidemiology of tuberculosis (TB) is significantly influenced by human migration. Immigrants from $\mathrm{TB}$ endemic nations continue to have TB rates that mirror their country of origin and account for a large proportion of active TB cases in industrialised nations [1-7]. In Australia the incidence of TB in 2009 was 6.4 per 100,000 people [8]. There is incomplete information about the rate amongst refugees and immigrants from high prevalence nations but studies have shown this to be higher than the general Australian population $[4,9,10]$.

The majority of Mycobacterium tuberculosis infections do not result in active disease. In greater than $90 \%$ of cases the individual remains asymptomatic and noninfectious, with so-called latent tuberculosis infection

\footnotetext{
* Correspondence: caroline.marshall@mh.org.au

'Department of Medicine, University of Melbourne, Grattan St Parkville,

Victoria 3050, Australia

${ }^{2}$ Victorian Infectious Diseases Service, Royal Melbourne Hospital, Grattan St

Parkville, Victoria 3050, Australia

Full list of author information is available at the end of the article
}

(LTBI) [11-14]. LTBI may progress to active disease and therefore potentially poses a major public health problem, especially in individuals infected with HIV. LTBI acquired prior to migration may reactivate after settlement in a new country. Effective diagnosis and treatment of LTBI are integral to TB prevention and control in developed nations. The American Thoracic Society and the Centers for Disease Control and Prevention recommends several regimens for treatment of LTBI. The regimen most commonly used in Australia is $300 \mathrm{mg}$ isoniazid once daily for nine months, which reduces the risk of active disease by approximately $80 \%$ [15]. Other less commonly used options include shorter, rifampicincontaining regimens. Isoniazid has been linked with serious side effects, the most severe being hepatotoxicity, so careful monitoring is needed $[15,16]$. Adherence may be variable, largely due to the lengthy treatment duration, lack of disease symptoms and potential adverse events [17-20]. It is thereby essential that patients on isoniazid are thoroughly informed about the treatment

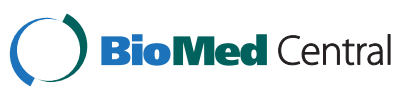


benefits, the importance of strict adherence to the medication regimen and the symptoms that may indicate serious side effects.

Immigrant and refugee patients often have low health literacy, posing challenges for health education [14]. Many refugees come from low socio-economic, nonEnglish speaking backgrounds or have limited education and poor knowledge of health and health services. Inadequate health literacy along with language barriers and different cultural and religious beliefs have been associated with lower adherence levels amongst these patients on isoniazid for LTBI [13,18,19,21-24].

In Victoria, patients requiring assessment and management of LTBI are usually referred by their general practitioner to infectious diseases clinics at tertiary hospitals. The Victorian Infectious Diseases Service (VIDS) at the Royal Melbourne Hospital (RMH) assesses large numbers of immigrants and refugees with active TB and LTBI at two clinics, the immigrant and refugee clinic and the $\mathrm{TB}$ clinic. Those attending the immigrant and refugee clinic are usually refugees or asylum seekers, who are often recently arrived and may have several medical problems. The patients attending the TB clinic tend to have a single problem and are more likely to be migrants. Currently, treating physicians educate patients about LTBI, isoniazid treatment and possible side effects. However, it is not known to what extent patients understand or remember information they have been given and whether this is influenced by education, ethnicity or gender. Anecdotal reports suggest that patients sometimes take medication incorrectly and forget important potential side effects. The objectives of this study were firstly, to assess refugee and immigrant patients' knowledge and understanding of information given about LTBI, the treatment regimen and potential side effects of isoniazid and secondly, to evaluate whether demographic factors were associated with knowledge and understanding in order to determine if better methods of providing information are required.

\section{Methods}

\section{Study design and data collection}

$\mathrm{RMH}$ is a university-affiliated, tertiary referral hospital. A convenience sample of patients attending the immigrant/ refugee and the TB clinics between May 5th and October 9th 2009 was recruited, consisting of patients referred specifically because of a positive QuantiFERON ${ }^{\circ}$-TB Gold (Cellestis Ltd, Carnegie, Victoria, Australia) or tuberculin skin test (1 $\mathrm{ml}$ of a $100 \mathrm{IU}$ PPD solution [CSL] injected intra-dermally). We intended to recruit at least 50 participants, based on what we perceived would give a reasonable indication of patient knowledge and what was feasible given the available personnel and time frame.
Patients diagnosed with LTBI were included if they were commencing or already taking isoniazid therapy for LTBI, were born in a country with a high prevalence of TB and had lived in Australia for less than ten years. We reviewed all histories of patients booked into each clinic to try to capture all potential participants. Approximately 55 patients newly commenced isoniazid during the study period, although we do not have denominator figures for those already on isoniazid. We did not favor or exclude on specific country of birth or language criteria, but there needed to be clinic space and both interviewer and interpreter time available after (See Additional file 1) or before (See Additional file 2) the patient appointment in order to make it feasible to conduct the interview.

Usual clinical management of LTBI at VIDS includes a detailed verbal explanation about LTBI and the isoniazid treatment regimen given by the treating physician at the initial consultation prior to commencement of treatment. Interpreters are used at every visit where necessary (including follow-up visits), although occasionally this may be via the telephone interpreter service. On most occasions, qualified interpreters are used, but there is no requirement for them to be qualified in medical terminology. Rarely, family members or friends are used as interpreters if there is no trained interpreter available. Commencement of isoniazid therapy would usually be deferred if there is no suitable interpreter available.

Written information is available in English and some of the other languages spoken by our patients, but is not always given to patients. The potential side effects of isoniazid are verbally described by the doctor, as is the course of action to take if these occur. Patients opting for treatment are usually given nine months of daily isoniazid. Alternative rifampicin-containing regimens are rarely used in our clinic. Pyridoxine is sometimes also prescribed [15]. Patients over the age of 35 are not usually offered isoniazid therapy because of the potential for age related hepatotoxicity [15]. Patients on isoniazid are always assessed after one month of treatment and then at one to three month intervals over the treatment course, depending on other co-morbidities and perceived need by treating physician. Liver function is tested at baseline but not routinely thereafter, unless the patient reports symptoms suggestive of hepatotoxicity. Education would usually be given by the treating physician at each visit depending on perceived need.

Two questionnaires were designed specifically for this study (See Additional file 1 and Additional file 2). We found no other published questionnaires covering areas that were of interest to the authors and none that had been administered to refugee patients. We pilot tested the questionnaires on nine patients over a two week period, resulting only in minor changes to the structure 
of the questionnaires, so all data from the pilot was included in the analysis.

Questionnaire 1 contained 23 questions consisting of eight socio-demographic questions and 15 to assess knowledge and understanding of LTBI, isoniazid regimen and side effects. It was administered to patients at the initial consultation when isoniazid treatment was first prescribed. The questionnaire was completed following the consultation to assess immediate recall of information provided by the doctor.

Questionnaire 2 consisted of the same questions as Questionnaire 1 with three additional questions regarding the number of missed days of isoniazid and whether the diagnosis had affected either the patient or their family's daily lives. It was administered to assess long term recall at a follow-up consultation after participants had been taking isoniazid for at least one month. Questionnaire 2 was administered prior to the patient seeing the doctor on these follow-up visits. Where possible, participants completed both Questionnaire 1 and Questionnaire 2. Questionnaires were read aloud to participants, through the use of an interpreter if necessary.

\section{Data analysis}

A "Total Knowledge Score" (TKS) was calculated for each participant by adding the score from five questions that were deemed (by consensus from the physicians in the clinic) to be the best indicators of overall LTBI knowledge, the treatment regimen and isoniazid side effects (including elements from questions 9, 10, 15, 19 and 20 see Additional file 2). Participants were awarded two points for knowing they had LTBI and one point for a reference to TB. Two points were given if the participant mentioned they were taking the same medication as prescribed and one point if they didn't distinguish between INH and pyridoxine. Knowing TB was spread via some form of microbe, that nausea/vomiting, abdominal pain or jaundice were side effects of INH and mentioning to stop medication if side effects occurred were awarded one point each giving a Total Knowledge Score out of nine. Binary TKS categories of high $(>6)$ and low $(\leq 6)$ were created as the outcome variable for regression models. Higher TKS indicated better results. Predictors of high TKS score were analysed using univariable and multivariable Poisson regression with robust standard errors. A Poisson approach was preferred over logistic modeling secondary to the relative frequency of the outcome variable (high TKS score was recorded for $48 \%$ of the sample). Poisson modeling also permitted direct calculation of relative risk whereas a logistic approach, in light of the frequency, would likely have returned overestimates of relative risk. Candidate predictors for inclusion in the multivariable model were identified as those considered to be clinically important by the researchers coupled with performance on univariable modeling. The number of outcomes $(n=22)$ limited adjusted modeling to a maximum of two concurrent explanatory variables to avoid over-fitting of the data. Collinearity between predictor variables was tested for. Interactions between predictors, as distinct from collinearity were examined using a likelihood-ratio test. Overall goodness of fit of the Poisson models was assessed using a Poisson chi-square goodness of fit test. Competing multivariable Poisson model solutions were compared using a bias-corrected Akaike Information Criterion [25] to identify the most parsimonious combination of predictor variables that was consistent with clinical expectations.

A "Total Side Effect Score" (TSES) was also generated by awarding one point for each of the seven potential side effects of isoniazid remembered by the participant (liver problems, nausea/vomiting, abdominal pain, jaundice, nerve problems, tingling/numbness in extremities and rash). Higher TSES indicated better results.

Data were analyzed using Microsoft Excel $^{\mathrm{m}} 2003$ and STATA version 10 (StataCorp, College Station, TX). Results were considered statistically significant if the pvalue was $<0.05$ and all reported confidence intervals are at $95 \%$.

\section{Ethics approval}

This study was approved by the Melbourne Health $\mathrm{Hu}$ man Research Ethics Committee Quality Assurance Stream. Verbal consent was obtained from all participants.

\section{Results}

\section{Profile of study participants}

Fifty-three patients were asked to take part in the study, of whom 52 agreed to participate. Thirty-two had already commenced isoniazid treatment and completed Ques1tionnaire 2 at a follow-up consultation. Twenty participants started on isoniazid during the study and completed Questionnaire 1 at their initial consultation. Of these, 14 completed Questionnaire 2 at a subsequent consultation, giving a total of 46 participants completing Questionnaire 2. Therefore, 20 patients completed Questionnaire 1, 46 completed Questionnaire 2 and 14 completed both.

Table 1 shows the socio-demographic characteristics of study participants. Participants came from 18 different countries (most commonly India, Ethiopia and Burma) and spoke 16 different primary languages (most commonly English and Nepalese). Twenty-two patients required interpreters, who were available for all consultations. Languages included Amharic, Arabic, Burmese, Chin Hakka, Hindi, Karen, Korean, Oromo, Swahili, Somali and Vietnamese. Questionnaires were translated directly to the participants. Fifteen participants were born in sub-Saharan Africa, 17 in Asia, 18 in the Indian sub-continent and 2 in the Middle East. Thirty-two 
Table 1 Socio-demographic characteristics of study participants

\begin{tabular}{|c|c|c|c|}
\hline $\begin{array}{l}\text { Population } \\
\text { characteristics }\end{array}$ & $\begin{array}{l}\text { Tertiary educated } \\
\qquad(\mathrm{N}=32) \\
n(\%)\end{array}$ & $\begin{array}{l}\text { Not tertiary educated } \\
\qquad \begin{array}{c}(\mathrm{N}=20) \\
n(\%)\end{array}\end{array}$ & $\begin{array}{c}\text { Total } \\
\left(\mathrm{N}=52^{\mathrm{a}}\right) \\
n(\%)\end{array}$ \\
\hline \multicolumn{4}{|l|}{ Clinic } \\
\hline Refugee \& Immigrant & $4(21.0)$ & $15(79.0)$ & $19(36.5)$ \\
\hline $\mathrm{TB}$ & $28(84.9)$ & $5(15.1)$ & $33(63.5)$ \\
\hline \multicolumn{4}{|l|}{ Gender } \\
\hline Male & $14(60.9)$ & $9(39.1)$ & $23(44.2)$ \\
\hline Female & $18(62.1)$ & $11(37.9)$ & $29(55.7)$ \\
\hline \multicolumn{4}{|l|}{ Interpreter Required } \\
\hline Yes & $6(27.3)$ & $16(72.7)$ & $22(42.3)$ \\
\hline No & $26(86.7)$ & $4(13.3)$ & $30(57.7)$ \\
\hline \multicolumn{4}{|l|}{ Reads English } \\
\hline Yes & $32(71.1)$ & $13(28.9)$ & $45(86.5)$ \\
\hline No & 0 & $7(100)$ & $7(13.5)$ \\
\hline \multicolumn{4}{|l|}{ Lived in a Refugee Camp } \\
\hline Yes & $2(20.0)$ & $8(80.0)$ & $10(19.2)$ \\
\hline No & $30(71.4)$ & $12(28.6)$ & $42(80.7)$ \\
\hline \multicolumn{4}{|l|}{ Time in Australia } \\
\hline$<6$ months & $2(28.6)$ & $5(71.4)$ & $7(13.5)$ \\
\hline 6 months- $<1$ year & $11(57.9)$ & $8(42.1)$ & $19(36.4)$ \\
\hline $1-<5$ years & $15(68.2)$ & $7(31.8)$ & $22(42.3)$ \\
\hline $5-10$ years & $4(100.0)$ & 0 & $4(7.7)$ \\
\hline \multicolumn{4}{|l|}{ Born in sub-Saharan Africa } \\
\hline Yes & $5(33.3)$ & $10(66.7)$ & $15(28.8)$ \\
\hline No & $27(72.9)$ & $10(27.1)$ & $37(71.2)$ \\
\hline \multicolumn{4}{|l|}{ Age (years) } \\
\hline Mean & 28.0 & 27.9 & 27.9 \\
\hline Median & 28 & 28 & 27.5 \\
\hline Range & $18-37$ & $18-36$ & $18-37$ \\
\hline
\end{tabular}

participants (61.5\%) had completed tertiary education, while two had no formal education at all.

\section{Participant understanding of latent tuberculosis and treatment}

The average TKS for Questionnaire 1 was $5.04 \pm 2.50$ (range 1-8) out of a total of nine. The average TKS for Questionnaire 2 was $6.23 \pm 1.80$ (range 3-9). Only three participants got the maximum score of nine (15\%). Seventy-five per cent $(n=15)$ of those who completed Questionnaire 1 and 89\% $(n=41)$ of participants who completed Questionnaire 2 understood they had LTBI. Typical correct responses were "non-active TB", "non-serious TB" or "sleeping TB". Responses to both Questionnaires 1 and 2 showed over $90 \%$ of participants knew that LTBI was asymptomatic and non-transmissible (Table 2).
There was a range of misconceptions about how TB was spread including via water, dust, wind or pollution.

There was good understanding of the treatment regimen; the reported medication dose matched that prescribed in $91.3 \%(n=42)$ of participants who completed Questionnaire 2. However, 37.0\% $(n=17)$ of participants stated they had missed 1-5 days of medication in the past month, with "forgetting" being the most common reason (Table 2).

\section{Participant understanding of isoniazid side effects}

The mean TSES for participants completing Questionnaires 1 and 2 was $5.0 \pm 1.8$ (range 2-7) and $3.5 \pm 1.8$ (range $0-7$ ) respectively. Only two participants who completed Questionnaire 2 could mention all seven side effects and two could not recall any (Table 3). Participants 
Table 2 Participant understanding of LTBI and isoniazid treatment

\begin{tabular}{|c|c|c|}
\hline $\begin{array}{l}\text { Understanding of LTBI } \\
\text { and isoniazid treatment }\end{array}$ & $\begin{array}{l}\text { Questionnaire } 1 \\
\qquad \begin{array}{c}\left(\mathrm{N}=20^{\mathrm{a}}\right) \\
n(\%)\end{array}\end{array}$ & $\begin{array}{l}\text { Questionnaire } \\
\qquad \begin{array}{c}\left(\mathrm{N}=46^{\mathrm{b}}\right) \\
n(\%)\end{array}\end{array}$ \\
\hline \multicolumn{3}{|l|}{ Why are you coming to this clinic? } \\
\hline Knew they had LTBI & $15(75.0)$ & $41(89.1)$ \\
\hline $\begin{array}{l}\text { Couldn't distinguish between TB \& } \\
\text { LTBI }\end{array}$ & $5(25.0)$ & $4(8.7)$ \\
\hline Unsure & $0(0.0)$ & $1(2.2)$ \\
\hline \multicolumn{3}{|l|}{ What is TB caused by? } \\
\hline $\begin{array}{l}\text { Knew it was caused by a } \\
\text { transmissible microbe }\end{array}$ & $9(45.0)$ & $22(47.8)$ \\
\hline Unsure & $11(55.0)$ & $24(52.2)$ \\
\hline \multicolumn{3}{|l|}{ Does this condition make you sick? } \\
\hline Yes & $0(0.0)$ & $2(4.4)$ \\
\hline No & $20(100.0)$ & $44(95.7)$ \\
\hline \multicolumn{3}{|l|}{$\begin{array}{l}\text { Can you give this condition to } \\
\text { anyone else? }\end{array}$} \\
\hline Yes & $1(5.0)$ & $1(2.3)$ \\
\hline No & $18(90.0)$ & $43(93.5)$ \\
\hline Unsure & $1(5.0)$ & $2(4.4)$ \\
\hline \multicolumn{3}{|l|}{ How will taking the tablets help you? } \\
\hline $\begin{array}{l}\text { Reduce the risk of active TB in the } \\
\text { future }\end{array}$ & $19(95.0)$ & $41(89.1)$ \\
\hline Unsure & $1(5.0)$ & $5(10.9)$ \\
\hline \multicolumn{3}{|l|}{$\begin{array}{l}\text { How many tablets will/do you take a } \\
\text { day? }\end{array}$} \\
\hline $\begin{array}{l}\text { Answer same as medication } \\
\text { prescribed }\end{array}$ & $14(70.0)$ & $42(91.3)$ \\
\hline $\begin{array}{l}\text { Answer different to medication } \\
\text { prescribed }\end{array}$ & $6(30.0)$ & $4(8.7)$ \\
\hline \multicolumn{3}{|l|}{$\begin{array}{l}\text { Do you know the name of the } \\
\text { tablets? }\end{array}$} \\
\hline Yes & $4(20.0)$ & $15(32.6)$ \\
\hline No & $16(80.0)$ & $31(67.4)$ \\
\hline \multicolumn{3}{|l|}{$\begin{array}{l}\text { How many times a day will/do you } \\
\text { take the tablets? }\end{array}$} \\
\hline Once & $16(80.0)$ & $45(97.8)$ \\
\hline Three Times & $0(0.0)$ & $1(2.2)$ \\
\hline Unsure & $4(20.0)$ & $0(0.0)$ \\
\hline \multicolumn{3}{|l|}{$\begin{array}{l}\text { How long will you need to take the } \\
\text { tablets for? }\end{array}$} \\
\hline 9 months & $16(80.0)$ & $35(76.1)$ \\
\hline 6-9 months & $4(20.0)$ & $7(15.2)$ \\
\hline 6 months & $0(0.0)$ & $3(6.5)$ \\
\hline Unsure & $0(0.0)$ & $1(2.2)$ \\
\hline
\end{tabular}

Table 2 Participant understanding of LTBI and isoniazid treatment (Continued)

\begin{tabular}{lcc}
\hline None & N/A & $25(54.3)$ \\
$1-5$ days & N/A & $17(37.0)$ \\
$5-10$ days & N/A & $4(8.7)$ \\
\hline LTBI = Latent Tuberculosis Infection; TB = Tuberculosis. \\
a 20 patients started on isoniazid and completed Questionnaire 1. \\
b 46 patients completed Questionnaire 2.
\end{tabular}

also proffered other side effects not included in the score, such as dizziness, change in urine colour, night sweats, acne and hair loss. All 46 participants who completed Questionnaire 2 said they would contact a doctor should they experience side effects and half said they would stop taking isoniazid $(\mathrm{n}=24,52.2 \%)$.

\section{Effect of socio-demographic determinants on participant understanding}

Results of the univariable and multivariable analyses showing predictor variables for TKS are shown in Table 4. Having an interpreter during the consultation was a significant predictor of a low TKS, in both univariable and multivariable analysis on Questionnaire 2.

\section{Discussion}

This is the first Australian study to provide a snapshot of the level of understanding about LTBI, isoniazid treatment and its side effects amongst refugee and immigrant patients attending a tertiary referral hospital. The study identified significant gaps with almost half not knowing how TB was spread and many not able to recall the side effects of isoniazid. The study identified an association between the use of an interpreter and having a low overall knowledge score. These findings demonstrate a critical need for improved strategies for the provision of health education to immigrant and refugee patients receiving treatment for latent tuberculosis to ensure its effectiveness.

Many misconceptions about the way TB is spread were reported. This finding is consistent with other studies in different ethnic groups, indicating that cultural beliefs may have a confounding influence on disease knowledge $[14,24,26]$. Furthermore, misconceptions about the spread of TB have previously been shown to impact upon an individual's willingness to take prophylactic medication and compliance with isoniazid [19,21,23,26].

The incomplete understanding of isoniazid side effects is similar to that found amongst Latino immigrants to the US [14]. Limited recall of the potential side effects of isoniazid amongst participants is concerning, most significantly because of the hepatotoxicity risk. Immigrant and refugee patients from non-English speaking backgrounds may have particular trouble understanding the complex side effects of isoniazid, especially if they have 
Table 3 Potential isoniazid side effects reported by participants who completed questionnaire 2

\begin{tabular}{lcc}
\hline & \multicolumn{2}{c}{$\begin{array}{c}\text { Participant responses } \\
\text { (N=46 }\end{array}$} \\
\cline { 2 - 3 } Isoniazid side effect & Yes & No \\
\hline Liver Problems & $25(54.3)$ & $21(45.7)$ \\
Nausea/ Vomiting & $25(54.3)$ & $21(45.7)$ \\
Abdominal Pain & $26(56.5)$ & $20(43.5)$ \\
Jaundice & $21(45.7)$ & $25(54.3)$ \\
Nerve Problems & $19(41.3)$ & $27(58.7)$ \\
Tingling/Numbness in extremities & $24(52.2)$ & $22(47.8)$ \\
Rash & $23(50.0)$ & $23(50.0)$ \\
\hline
\end{tabular}

a 46 participants completed Questionnaire 2.

had limited education about health. Medical terms for these side effects may not translate specifically into other languages and the meaning may be difficult to convey.

Having an interpreter was significantly associated with a $69 \%$ lower chance of having a high score after adjustment for clinic day. This finding has not been described before in similar studies. It may indicate inadequate training of interpreters with either lack of knowledge of particular terms used in discussion of LTBI or absence of such words in some languages, making direct translation impossible. Another possible explanation is that the need for an interpreter is a marker for major differences in understanding of health, illness and healing that go beyond the capacity of an interpreter to deal with. Alternatively, English-speaking clinicians in a majority English-speaking culture may not communicate well with patients who need interpreters.
Nearly $46 \%$ of patients reported missing treatment for between one and ten days in the prior month, with most reporting that they had forgotten to take their tablets. This is a concerning figure with potential impacts on the effectiveness of treatment. Whilst health education activities may not improve memory, repeated explanations about the potential consequences of forgetting may help to crystallize the importance of good adherence. Frequent clinic visits, for example monthly, may also help to reinforce these messages and improve adherence. Newer treatment regimens, such as weekly isoniazid and rifapentine for 12 weeks, are simpler, may improve adherence and may be suitable for these patients [27]. This regimen was not available in Australia at the time of the study.

The study has several potential limitations. The number of participants was relatively small. Despite this, there were still some significant results found in the multivariable regression. Although a standardised explanation was not provided by physicians, a similar way of explaining concepts is used by the doctors in the clinics and there is very little turn-over of doctors. We cannot be certain, however, whether all concepts tested on the questionnaires were explained to all patients. There may also have been a loss of information accuracy through the use of an interpreter. Furthermore, baseline knowledge of participants was not tested. The questionnaire utilised was developed specifically for the purpose of this study and has not been used within other population groups. Whilst it has face validity, it may need to be validated in other studies.

\section{Conclusions}

This study found that refugee and immigrant patients attending two infectious diseases outpatient clinics at a

Table 4 Predictors of total knowledge score (Questionnaire 2)

\begin{tabular}{|c|c|c|c|c|c|c|c|c|}
\hline \multirow[b]{5}{*}{ Variables } & \multicolumn{8}{|c|}{ Total knowledge Score- questionnaire 2} \\
\hline & \multicolumn{5}{|c|}{ Univariable analysis } & \multicolumn{3}{|c|}{ Multivariable analysis } \\
\hline & High score $^{a}$ & Low score $^{b}$ & & & & & & \\
\hline & $\mathrm{N}=22$ & $N=24$ & & & & & & \\
\hline & $(n)$ & $(n)$ & uIRR & $(95 \% \mathrm{Cl})$ & $P$ & alRR & $(95 \% \mathrm{Cl})$ & $P$ \\
\hline Age, years & 22 & 24 & 1.02 & $(0.89-1.75)$ & 0.737 & & & \\
\hline Interpreter & 6 & 15 & 0.23 & $(0.07-0.79)$ & 0.019 & 0.313 & $(0.14-0.69)$ & 0.004 \\
\hline I \& R Clinic & 7 & 10 & 0.66 & $(0.20-2.19)$ & 0.490 & 1.75 & $(0.93-3.30)$ & 0.083 \\
\hline Male sex & 9 & 12 & 0.69 & $(0.22-2.23)$ & 0.537 & & & \\
\hline Tertiary educated & 16 & 13 & 2.26 & $(0.66-7.76)$ & 0.197 & & & \\
\hline Lived in a refugee camp & 3 & 6 & 0.47 & $(0.10-2.18)$ & 0.338 & & & \\
\hline Mean number of clinic visits & 2.5 & 2.6 & 5.53 & $0.59-51.64)$ & 0.134 & & & \\
\hline Residence in Australia $>1$ year & 13 & 12 & 1.44 & $(0.45-4.64)$ & 0.537 & & & \\
\hline Sub-Saharan African country of birth & 7 & 6 & 1.13 & $(0.32-3.98)$ & 0.845 & & & \\
\hline
\end{tabular}

I \& R Clinic = Immigrant and Refugee Clinic; $\mathrm{Cl}=$ Confidence Interval; ulRR = unadjusted Incidence Rate Ratio; alRR = adjusted Incidence Rate Ratio.

${ }^{a}$ High Score, greater than $6 / 9$.

b Low Score, less than or equal to $6 / 9$. 
tertiary referral hospital had a suboptimal level of understanding and knowledge of latent TB, its treatment regimen and treatment side effects. These findings have significant implications for clinical practice. The association between having an interpreter and low knowledge and understanding is particularly worrying as it suggests that patients requiring an interpreter may be at a disadvantage, for which use of an interpreter is insufficient to compensate. Medical education programs are needed to improve interpreters' knowledge about latent TB (and other diseases) in order to transfer accurate health messages to patients. There is currently no specialist training for interpreters in medical vocabulary and no requirement that there should be such training. Any training that takes place is through self-funded personal development. Outsourcing of interpreting services may prevent the accumulation of organisational experience in the field or in specific institutions. One possible avenue to address this deficit is offering certified short courses for interpreters who work in health care settings. Similarly, immigrant and refugee populations would benefit from linguistically and culturally appropriate health education. This would be particularly beneficial for refugee patients from non-English speaking backgrounds who may have low health literacy and limited access to accurate information. Information is available in some languages other than English, but not in the languages most commonly spoken by our patients. Translation is limited by lack of resources. Another, more complex response would be the development of a bilingual health worker role to provide support and education to individual patients and ethnic communities beyond simple interpreting. Findings from this study could help to inform providers of TB care how best to educate and motivate patients from very different cultural and linguistic backgrounds about the importance of adherence to treatment for latent TB.

\section{Additional files}

Additional file 1: Survey instrument. This file contains Questionnaire 1 administered to participants. Key sections have been reported in this paper

Additional file 2: Survey instrument. This file contains Questionnaire 2 administered to participants. Key sections have been reported in this paper.

\section{Competing interests}

The authors declare that they have no competing interests.

\section{Authors' contributions}

KB participated in design of the study, collected and analysed the data and drafted the manuscript. BAB assisted in study conception and design, oversaw data collection and analysis and helped draft the manuscript. $\mathrm{KL}$ assisted in study conception and design, oversaw data collection and analysis and helped draft the manuscript. CL oversaw data collection and analysis and helped draft the manuscript. DO oversaw data collection and analysis and helped draft the manuscript. CM assisted in study conception and design and coordination, oversaw data collection and analysis and helped draft the manuscript. All authors read and approved the final manuscript.

\section{Authors' information}

KB was an honours science student in the Department of Medicine at the University of Melbourne at the time of this study.

$B A B$ is an infectious diseases physician at the Royal Melbourne Hospital and Professor at the Department of Medicine, University of Melbourne.

$\mathrm{KL}$ is an infectious diseases physician at the Royal Melbourne Hospital and Associate Professor at the Department of Epidemiology and Preventive Medicine, Monash University.

$\mathrm{CL}$ was an infectious diseases physician at the Royal Melbourne Hospital and PhD student at the Department of Medicine, University of Melbourne at the time of this study.

DO is an infectious diseases physician at the Royal Melbourne Hospital and Geelong Hospital.

CM is an infectious diseases physician at the Royal Melbourne Hospital and Associate Professor at the Department of Medicine, University of Melbourne.

\section{Acknowledgements}

The authors would like to acknowledge the outpatient clinic manager, Paulette Manton, and the clinic nurse, Elizabeth Matchett. We would also like to thank Tim Spelman for helpful advice about the statistical analysis.

\section{Author details}

${ }^{1}$ Department of Medicine, University of Melbourne, Grattan St Parkville, Victoria 3050, Australia. ${ }^{2}$ Victorian Infectious Diseases Service, Royal Melbourne Hospital, Grattan St Parkville, Victoria 3050, Australia. ${ }^{3}$ Department of Epidemiology and Preventive Medicine, Monash University, 99 Commercial Road, Melbourne, Victoria 3000, Australia. ${ }^{4}$ Department of Infectious Diseases, Geelong Hospital, Bellerine Street, Geelong, Victoria 3220, Australia

Received: 21 May 2013 Accepted: 26 August 2013

Published: 29 August 2013

\section{References}

1. Walls T, Shingadia D: The epidemiology of tuberculosis in Europe. Arch Dis Child 2007, 92:726-729.

2. Levesque JF, Dongier PBP: Acceptance of screening and completion of treatment for latent tuberculosis infection among refugee claimants in Canada. Int J Tuberc Lung Dis 2004, 8:711-717.

3. Cain KP, Haley CA, Armstrong LR: Tuberculosis among foreign-born persons in the United States. Am J Resp Crit Care Med 2007, 175:75-79.

4. Gibney KB, Leder K, Torresi J, Marshall C, Matchett E, Ebeling PR, Biggs BA: Vitamin $\mathrm{D}$ deficiency is associated with tuberculosis and latent tuberculosis infection in immigrants from Sub-Saharan Africa. Clin Infect Dis 2008, 46:443-446.

5. Matteelli A, Casalini C, Raviglione MC, Scolari C, Bombana E: Supervised preventive therapy for latent tuberculosis infection in illegal immigrants in Italy. Am J Resp Crit Care Med 2000, 162:1653-1655.

6. Centers for Disease Control and Prevention: Trends in tuberculosis- United States, 2008. Morb Mortal Weekly Report 2009, 58:249-253.

7. Lopez-Velez R, Huerga H, Turrientes MC: Infectious diseases in immigrants from the perspective of a tropical medicine referral unit. Am J Trop Med Hyg 2003, 69:115-121.

8. World Health Organisation: Australia tuberculosis profile 2009. World Health Organisation; 2011. http://www.who.int/tb/country/data/profiles/en/index.html.

9. Marks GB, Bai J, Simpson SE: Incidence of tuberculosis among a cohort of tuberculin-positive refugees in Australia: Am J Resp Crit Care Med 2000, 162:1851-1854.

10. Gibney KB, Mihrshahi S, Torresi J, Marshall C, Leder K, Biggs BA: The profile of health problems in African immigrants attending an infectious disease unit in Melbourne, Australia. Am J Trop Med Hyg 2009, 80:805-811.

11. Maartens G, Wilkinson R: J: Tuberculosis. Lancet 2007, 370:2030-2043.

12. Centers for Disease Control and Prevention: Core curriculum on tuberculosis. 4th edition. Atlanta, GA: National Center for HIV/AIDS, Viral Hepatitis, STD, and TB Prevention; 2008.

13. Hirsch-Moverman Y, Daftary A, Franks J, Colson PW: Adherence to treatment for latent tuberculosis infection: systematic review of studies in the US and Canada. Int J Tuberc Lung Dis 2008, 12:1235-1254. 
14. Ailinger RL, Armstrong R, Nguyen N, Lasus H: Latino immigrants' knowledge of tuberculosis. Pub Health Nursing 2004, 21:519-923.

15. American Thoracic Society and Centers for Disease Control and Prevention: Targeted tuberculin testing and treatment of latent tuberculosis infection. Am J Resp Crit Care Med 2000, 161:S221-S247.

16. Menzies $D$, Long $R$, Trajman A: Adverse events with 4 months of rifampin therapy or 9 months of isoniazid therapy for latent tuberculosis infection. Ann Int Med 2008, 149:689-697.

17. Page KR, Sifakis F, Montes De Oca R, Cronin WA, Doherty MC, Federline L, Bur S, Walsh T, Karney W, Milman J, Baruch N, Adelakun A, Dorman SE: Improved adherence and less toxicity with rifampin vs isoniazid for treatment of latent tuberculosis: a retrospective study. Arch Intern Med 2006, 166:1863-1870.

18. Alilinger RL, Moore JB, Nguyen N, Lasus H: Adherence to latent tuberculosis infection therapy among Latino immigrants. Public Health Nurs 2006, 23:307-313.

19. Ito KL: Health culture and the clinical encounter: Vietnamese refugees' responses to preventive drug treatment of inactive tuberculosis. Med Anthropol Q 1999, 13:338-364.

20. Hess K, Goad J, WU J, Johnson K: Isoniazid completion rates of latent tuberculosis infection among college students managed by a community pharmacist. J Am Coll Health 2009, 57:553-555.

21. Wyss $L L$, Alderman MK: Using theory to interpret beliefs in migrants diagnosed with latent TB. Online J Iss Nurs 2006, 12:7.

22. Hovell M, Blumberg E, Gil-Trejo L: Predictors of adherence to treatment for latent tuberculosis infection in high-risk Latino adolescents: a behavioral epidemiological analysis. Soc Sci Med 2003, 56:1789-1796.

23. Shieh FK, Snyder G, Horsburgh CR, Bernardo J: Predicting non-completion of treatment for latent tuberculosis infection. Am J Resp Crit Care Med 2006, 174:717-721

24. Coreil J, Lauzardo M, Heurtelou M: Cultural feasibility assessment of tuberculosis prevention among persons of Haitian origin in South Florida. J Imm Health 2004, 6:63-69.

25. Kamo K, Yanagihara H, Satoh K: Bias-corrected AIC for selecting variables in Poisson regression models. Commun Stat Theory Methods 2013, 42:1911-1921.

26. Houston HR, Harada N, Makinodan T: Development of a culturally sensitive educational intervention program to reduce the high incidence of tuberculosis among foreign-born Vietnamese. Ethn Health 2002, 7:255-257.

27. Centers for Disease Control and Prevention: Recommendations for Use of an isoniazid-rifapentine regimen with direct observation to treat latent mycobacterium tuberculosis infection. MMWR 2011, 60:1650-1653.

doi:10.1186/1756-0500-6-342

Cite this article as: Butcher et al:: Understanding of latent tuberculosis, its treatment and treatment side effects in immigrant and refugee patients. BMC Research Notes 2013 6:342.

\section{Submit your next manuscript to BioMed Central and take full advantage of:}

- Convenient online submission

- Thorough peer review

- No space constraints or color figure charges

- Immediate publication on acceptance

- Inclusion in PubMed, CAS, Scopus and Google Scholar

- Research which is freely available for redistribution

Submit your manuscript at www.biomedcentral.com/submit
C Biomed Central 